\title{
PAPERS
}

\section{Photothermal laser ablation of Barrett's oesophagus: endoscopic and histological evidence of squamous re-epithelialisation}

\author{
C P Barham, R L Jones, L R Biddlestone, R H Hardwick, N A Shepherd, H Barr
}

\begin{abstract}
Background-Barrett's oesophagus is acquired by severe gastro-oesophageal reflux and is a premalignant condition. Acid suppression or anti-reflux surgery alone do not cause significant regression of the metaplastic mucosa nor reduce the malignant potential. Recent reports have suggested that the combination of mucosal ablation with acid suppression may result in squamous regeneration.
\end{abstract}

Aims-To destroy Barrett's mucosa by thermal ablation (in the setting of acid suppression) and so induce squamous regeneration.

Patients-Sixteen patients with nondysplastic Barrett's oesophagus were recruited from a surveillance programme. All had been on a proton pump inhibitor. Methods-At intervals, non-circumferential areas of columnar mucosa were ablated using the KTP laser. Acid suppression was obtained with $40 \mathrm{mg}$ omeprazole daily. Multiple biopsy specimens were obtained for histological examination from ablated areas.

Results-Ablation of all areas of glandular mucosa resulted in squamous regeneration. The number of treatments required depended on the length of the Barrett's segment. In 11 patients there was evidence of squamous regeneration over remaining Barrett's glands (in some of the posttreatment biopsy specimens) whilst in nine patients squamous metaplasia was seen within Barrett's glands.

Conclusion-Mucosal ablation of Barrett's oesophagus by laser, in the setting of acid suppression, results in squamous regeneration (though some burying of Barrett's glands did occur).

(Gut 1997; 41: 281-284)

Keywords: Barrett's oesophagus; laser; dysplasia; columnar-lined oesophagus; cancer

Barrett's or columnar-lined oesophagus (CLO) is acquired by severe gastro-oesophageal reflux disease and has the potential for malignant transformation. Barrett's oesophagus is reported in approximately $10-20 \%$ of endoscopies carried out for reflux disease and the incidence of adenocarcinoma in CLO is approximately one case developing per 200 patient years ${ }^{23}-30-40$ times higher than the rate in the general population. ${ }^{1}$ Although oesophageal adenocarcinoma is an uncommon tumour, it is the one gastrointestinal malignancy that is showing an alarming increase in incidence. ${ }^{45}$ As CLO is a premalignant condition many authors advocate regular surveillance with multiple biopsies to detect the development of dysplasia and carcinoma. ${ }^{6}$ Once detected, however, the treatment for oesophageal carcinoma is radical surgical excision (with its attendant morbidity and mortality), though generally less than $40 \%$ of patients are amenable to curative surgery. Previous reported attempts at treating the underlying cause of the CLO (namely, gastrooesophageal reflux disease) by either surgery ${ }^{7}$ or medical therapy ${ }^{10}$ have generally failed to produce regression of the metaplastic mucosa. Even the proton pump inhibitors have at best resulted in only partial regression. ${ }^{11}{ }^{12}$ Recently, an animal study, ${ }^{13}$ a case report, ${ }^{14}$ and a paper ${ }^{15}$ have described the regression of CLO following laser ablation in the setting of maximal acid suppression. The aim of this study was to try to replicate the findings of these reports and to determine whether the regression could be maintained on the return to the patient's standard anti-reflux therapy.

\section{Methods}

PATIENTS

Sixteen patients (12 men) of median age 63 years (range 35-76) were recruited from the Gloucestershire Royal Hospital Barrett's surveillance programme (table 1). All patients had more than $3 \mathrm{~cm}$ of circumferential nondysplastic CLO confirmed histologically. All had been on omeprazole prior to the study with improvement of reflux symptoms but no regression of the CLO. No patient had had surgery to the upper gastrointestinal tract and none was on medication known to affect gastrointestinal motility. Written informed consent was obtained from all patients and the 
TABLE $1 \quad$ Patient and treatment details showing number of laser sessions, number of biopsy sets containing some concealed Barrett's glands and the number of biopsy sets demonstrating some squamous regeneration in previous Barrett's glands

\begin{tabular}{llllllll}
\hline Patient & Age & Sex & $\begin{array}{l}\text { Laser } \\
\text { treatments }\end{array}$ & $\begin{array}{l}\text { Treatment } \\
\text { completed }\end{array}$ & $\begin{array}{l}\text { Initial } \\
\text { histology }\end{array}$ & $\begin{array}{l}\text { Buried } \\
\text { CLO }\end{array}$ & $\begin{array}{l}\text { Gland } \\
\text { involvement }\end{array}$ \\
\hline 1 & 51 & $\mathrm{M}$ & 2 & Yes & Intestinal & 1 & 1 \\
2 & 76 & $\mathrm{M}$ & 3 & Yes & Intestinal & 2 & 1 \\
3 & 65 & $\mathrm{M}$ & 3 & Yes & Intestinal & 1 & 1 \\
4 & 53 & $\mathrm{M}$ & 4 & Yes & Intestinal & 3 & 0 \\
5 & 36 & $\mathrm{~F}$ & 5 & Yes & Intestinal & 2 & 1 \\
6 & 67 & $\mathrm{M}$ & 3 & Yes & Intestinal & 2 & 1 \\
7 & 35 & $\mathrm{M}$ & 5 & Yes & Fundic & 0 & 0 \\
8 & 71 & $\mathrm{M}$ & 3 & Yes & Intestinal & 4 & 2 \\
9 & 43 & $\mathrm{~F}$ & 2 & Yes & Cardiac & 1 & 2 \\
10 & 60 & $\mathrm{M}$ & 5 & Yes & Intestinal & 1 & 1 \\
11 & 60 & $\mathrm{~F}$ & 6 & Yes & Intestinal & 3 & 3 \\
12 & 73 & $\mathrm{M}$ & 3 & Yes & Intestinal & 0 & 0 \\
13 & 70 & $\mathrm{~F}$ & 4 & Yes & Intestinal & 0 & 0 \\
14 & 38 & $\mathrm{M}$ & 1 & No & Intestinal & 0 & 0 \\
15 & 75 & $\mathrm{M}$ & 4 & No & Intestinal & 2 & 0 \\
16 & 65 & $\mathrm{M}$ & 1 & No & Intestinal & 0 & 0 \\
\end{tabular}

CLO, columnar-lined oesophagus.

study was approved by the local ethical committee.

STUDY DESIGN

All patients underwent a baseline endoscopy to obtain photographic evidence of the extent of the CLO, and histological evidence from multiple sites and levels to confirm non-dysplastic glandular epithelium. Under intravenous sedation (midazolam, Roche) non-circumferential patches of the glandular epithelium (approximately $30 \%$ a treatment session) were ablated using multiple point burns of the KTP laser (Laserscope, San Jose, California, USA). The KTP laser is a frequency doubled NdYag laser with a crystal of potassium titanyl phosphate (KTP) placed in the laser beam to reduce its wavelength from $1064 \mathrm{~nm}$ to $532 \mathrm{~nm}$. The laser was set to deliver 20 Watts in one second bursts to limit its destructive capacity, induce minimal fibrosis, but encourage healing by regeneration. The point burn produces a small white thermal injury on the oesophageal mucosa that is readily visible. Earlier work using thermal imaging techniques and histological assessment had shown this to be the optimal laser system and treatment method producing surface (mucosal) temperatures in the oesophagus of more than $65^{\circ} \mathrm{C}$ with external (serosal) temperatures of only $21^{\circ} \mathrm{C} .^{16}$ Patients were commenced on $40 \mathrm{mg}$ omeprazole daily (in divided doses) to obtain maximal acid suppression. At six weekly intervals patients underwent further endoscopy and multiple biopsy specimens were obtained to document changes to the treated epithelium prior to further laser ablation of persisting glandular mucosa. Treatments were continued until eradication of the CLO was achieved. On completion of treatment, the normal maintenance dose of omeprazole (20 mg daily) was restarted and the patients were re-entered into the yearly surveillance programme.

\section{Results}

To date, 54 laser ablations have been employed on the 16 patients with 13 having completed the study. Of the patients who have finished their treatment the median number of laser ablations was three (range 1-6). All laser treat-
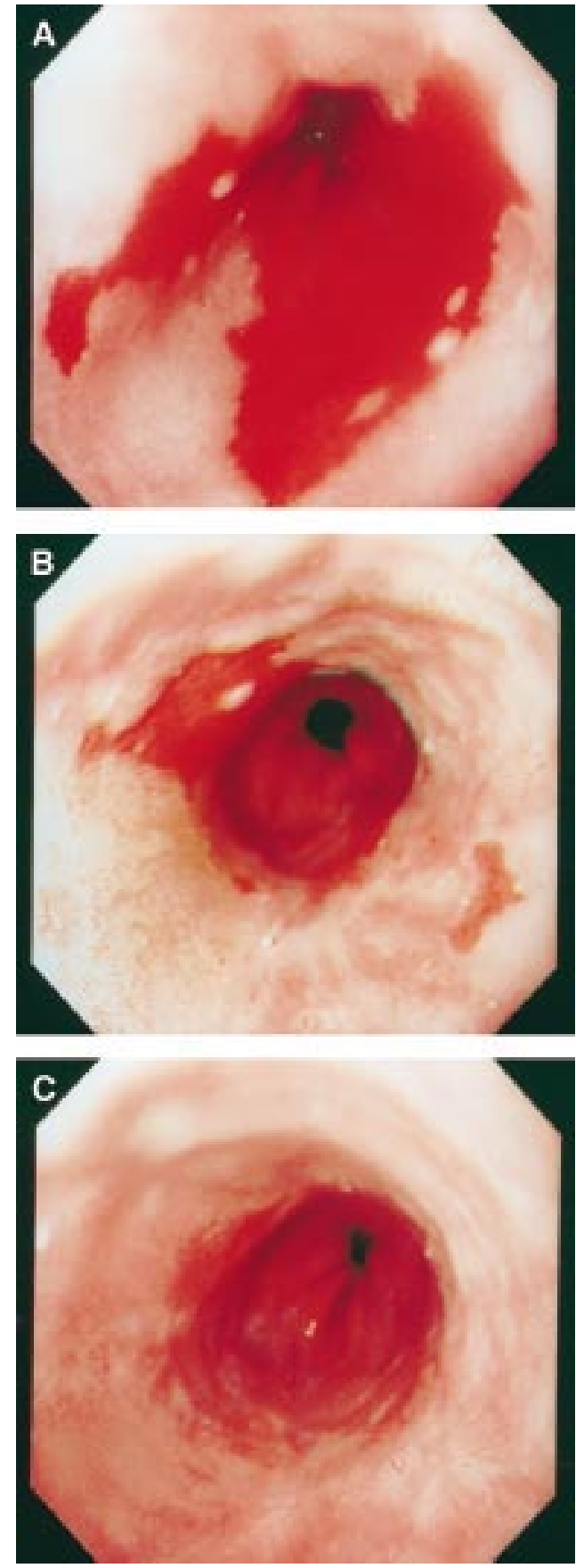

Figure 1: Sequence of photographs revealing squamous regeneration following laser thermal ablation in a patient with Barrett's oesophagus: $(A)$ before treatment; $(B)$ following ablation to the area on the right of plate $(A) ;(C)$ following ablation to the remaining areas of Barrett's mucosa.

ments resulted in squamous regeneration confirmed endoscopically (fig 1) and histologically (fig 2, table 1). In 11 patients some of the biopsy specimens following treatment ( 23 of 54 sets) revealed persisting Barrett's glands under areas of squamous regeneration (fig 2). In nine patients some of the post-treatment biopsy specimens (13 of 54) demonstrated squamous regeneration within previous Barrett's glands. In remaining areas of CLO (during the treatment phase) no histological type change occurred and there was no evidence of the development of dysplasia. Apart from minor 

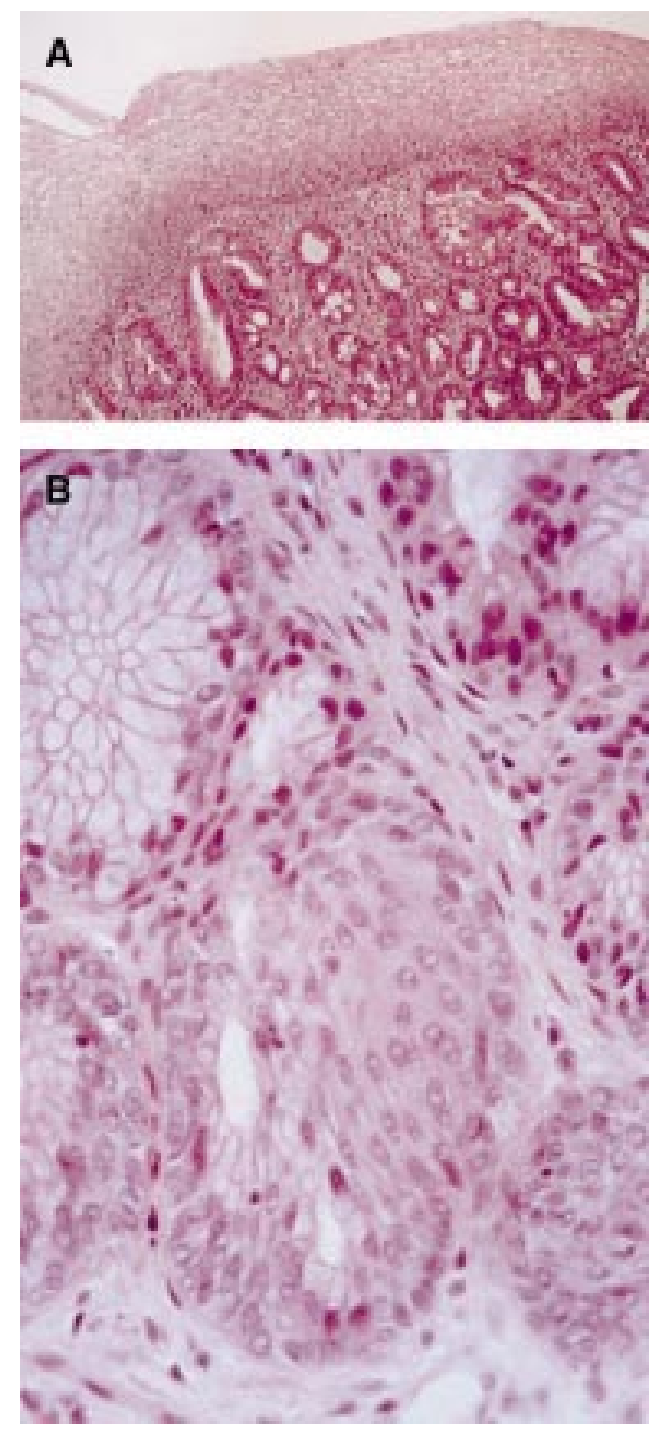

Figure 2: Histological appearance of biopsy specimens obtained from areas of squamous regeneration following laser thermal ablation. (A) Squamous epithelium overlying persisting Barrett's glands. (B) Squamous metaplasia in a deep Barrett's gland in the centre of the figure contrasting with the uninvolved gland in the upper left area.

retrosternal discomfort for 48 hours after the laser, there have been no treatment related complications. There has been no evidence of reversion to surface Barrett's mucosa in the 13 patients who have finished their treatment but follow up has been short (3-18 months).

\section{Discussion}

The incidence of adenocarcinoma of the oesophagus has shown a dramatic rise in both Europe and the USA over recent years. The cause of this rise appears to be related to Barrett's oesophagus which has approximately a $10 \%$ risk of developing adenocarcinoma (higher if dysplasia is present). The identification of Barrett's oesophagus as a premalignant condition and the poor survival of patients with adenocarcinoma makes eradication of Barrett's oesophagus an attractive idea. As Barrett's oesophagus occurs as a consequence of long term severe acid reflux, it follows that eradication of acid reflux may result in a reversion of the glandular mucosa to squamous epithelium. This does not seem to be the case as previous studies have failed to show consistent regression of the glandular mucosa on antacid therapy, $\mathrm{H}_{2}$ antagonists, or with anti-reflux surgery. ${ }^{7-10}$ Whilst occasional reports have suggested that the proton pump inhibitors may induce partial regression, others have found no change in the extent of the glandular mucosa. ${ }^{11} 12$

Recent reports have shown that destruction of the glandular mucosa in patients with high grade dysplasia using photodynamic therapy (in combination with acid suppression) has resulted in eradication of the dysplastic mucosa ${ }^{17}$ and has produced squamous regeneration. ${ }^{17}{ }^{18} \mathrm{An}$ animal study, ${ }^{13}$ a case report, ${ }^{14}$ the treatment of 10 patients by Berenson et $a l,{ }^{15}$ and this study have shown that photoablation of the glandular mucosa with laser (in conjunction with acid suppression) also results in squamous regeneration.

Histological assessment during and after laser treatment has shown that squamous regeneration occurs, not only on the surface of the oesophagus, but also within previous Barrett's glands. The source of the regenerated squamous cells is not known but Berenson et al ${ }^{15}$ have suggested that regrowth occurs from adjacent squamous cells and from progenitor cells within the glandular mucosa itself. Our finding of squamous regeneration within Barrett's glands would support the idea of at least some of the squamous cells originating from pluripotential cells in the base of these glands. The presence of some glandular elements concealed beneath the regenerated squamous cells is also important to note. This finding was seen in 11 of the patients (in 23 of 54 sets of biopsy specimens) and was also noted in Berenson et al's study. This feature may be the result of an inadequate and uneven depth of thermal damage in some areas (produced by multiple point burns) leading to a persistence of the glandular elements. Greater depth of thermal destruction may reduce this finding (though with the possible risk of fibrosis) and this needs examining. One might expect photodynamic treatment of Barrett's mucosa to prevent the occurrence of buried glands by producing a more even area of photothermal ablation. This, however, does not seem to be the case as buried glands still occur. ${ }^{17}$ The significance of this finding is not clear. It may well be that buried glands disappear over the long term but, at the moment, follow up has been too short as some of the patients have not completed treatment and, in others who have completed treatment, biopsy specimens have not been taken following laser treatment.

While the concealment of some glandular elements is a potentially worrying finding, it may not, in fact, be important if the layer of squamous cells protects against their further exposure to acid reflux. The presence of a surface squamous mucosa should not prevent the early detection of dysplasia provided surveillance endoscopy and multiple deep biopsy specimens from multiple levels are regularly obtained. In any event these patients will need 
long term follow up before we can determine the final outcome of their oesophageal mucosa. While the follow up in this study has been short, the finding that no significant recurrence of surface Barrett's mucosa has occurred on the return to maintenance omeprazole treatment is encouraging.

The finding that squamous regeneration can occur after laser ablation is an exciting development in the study of Barrett's oesophagus. Many questions and problems need addressing before this technique can be adopted on a wide scale. One particular problem is the endoscopic identification of the gastro-oesophageal junction. This will always be difficult and ablating glandular mucosa will only be of benefit if the risk of malignant change is related to the length of the glandular mucosa. There would be no point in restoring $90 \%$ of the Barrett's mucosa to a squamous epithelium if the $10 \%$ that remained carried the same malignancy risk as the original length of CLO. Long term follow up of these laser-treated patients is required to determine whether the squamous regeneration can be maintained on return to normal acid-reducing therapies. In addition, combining laser ablation with anti-reflux surgery requires investigation. Finally, photoablation of Barrett's oesophagus may be an appropriate strategy for treating patients with dysplasia and even early adenocarcinoma who would not be suitable for major oesophageal surgery.

1 Spechler SJ, Goyal RK. Barrett's esophagus. N Engl f Med 1986; 315: 362-71.

2 Spechler SJ, Robbins AH, Rubins HB, Barham CP, Jones Spechler SJ, Robbins AH, Rubins HB, Barham CP, Jones
RJ, Biddlestone LR, et al. Adenocarcinoma and Barrett's RJ, Biddlestone LR, et al. Adenocarcinoma and Barrett's 927-33.
3 Cameron AJ, Ott BJ, Payne WS. The incidence of adenocarcinoma in columnar-lined (Barrett's) esophagus. adenocarcinoma in columnar-lined

4 Sievsema PD, Dees J, Tilanis HW, Kok TC, Hardijk ML, Van-Blankenstein $M$. Early detection and treatment of oesophageal and gastric cancer. The Rotterdam oesophageal tumour study group. Neth $\mathcal{F}$ Med 1995; 47: 76-86.

5 Mckinney A, Sharp L, Macfarlane GJ, Muir CS. Oesophageal and gastric cancer in Scotland 1960-1990. Br f Cancer 1995; 71: 411-5.

6 Spechler SJ. Barrett's esophagus: what's new and what to do? Am $\mathcal{F}$ Gastroenterol 1989; 84: 220-3.

7 Starnes VA, Adkins RB, Ballinger JF, Sawyers JL. Barrett's esophagus: a surgical entity. Arch Surg 1984; 119: 563-7.

8 Williamson WA, Ellis FH, Gibb SP, Shahian DM, Aretz HT. Effect of antireflux operation on Barrett's mucosa. Ann Thorac Surg 1990; 49: 537-42.

9 Sampliner RE, Garewal HS, Fennerty MB, Aickin M. Lack of impact of therapy on extent of Barrett's esophagus in 67 patients. Dig Dis Sci 1990; 35: 93-6.

10 Castell DO. Medical management of the patient with Barrett's esophagus. In: Spechler SJ, Goyal RK, eds. Barrett's esophagus: pathophysiology, diagnosis and management. New York: Elsevier Science, 1985: 199-209.

11 Gore S, Healey CJ, Sutton R, Eyre-Brook IA, Gear MWL, Shepherd NA, et al. The regression of columnar lined (Barrett's) oesophagus with continuous omeprazole therapy. Aliment Pharmacol Ther 1993; 7: 623-8.

12 Sampliner RE, Mackel C, Jennings D, Greski-Rose P. Effect of 12 months of a proton pump inhibitor (Lansoprazole) on Barrett's esophagus: a randomized trial [abstract]. Gason Barrett's esophagus: a randont

13 Fink MA, Martin CJ, Ewing HP, Thompson ME, Macher D, Rhode J. Reversal of experimental Barrett's esophagus by endoscopic laser ablation and reduction of acid reflux [abstract]. Gastroenterology 1992; 102: A924.

14 Sampliner RE, Hixson LJ, Fennerty MB, Garewal HS. Regression of Barrett's esophagus by laser ablation in an antacid environment. Dig Dis Sci 1993; 38: 365-8.

15 Berenson MM, Johnson TD, Markowitz NR, Buchi KN, Samowitz WS. Restoration of squamous mucosa after ablation of Barrett's esophageal epithelium. Gastroenterology 1993; 104: 1686-91.

16 Dix T, Barr H. Thermal imaging to compare three lasers for the photodestruction of superficial tissue in columnar lined oesophagus [abstract]. Lasers Med Sci 1994; 9: A221.

17 Barr H, Shepherd NA, Dix A, Roberts DJH, Tan WC, Krasner N. Eradication of high-grade dysplasia in columnar-lined (Barrett's) oesophagus by photodynamic therapy with endogenously generated protoporphyrin IX. Lancet 1996; 348: 584-5.

18 Overholt BF, Panjehpour M. Photodynamic therapy in Barrett's esophagus: reduction of specialized mucosa, ablation of dysplasia and treatment of superficial esophageal cancer. Semin Surg Oncol 1995; 11: 372-6. 